\title{
ARTÍCULOS
}

\section{LAS ELECCIONES SINDICALES DE 1982}

\author{
1982 Union Elections
}

\author{
Juan José Suárez Sánchez \\ UNED \\ jsuarez59@alumno.uned.es \\ Orcid: 0000-0003-4851-8274
}

Cómo citar este artículo/Citation:

Juan José Suárez Sánchez, "Las elecciones sindicales de 1982”, Hispania Nova, 19 (2021): 484-521.

DOI: $\underline{\text { https://doi.org/10.20318/hn.2021.5889 }}$

\begin{abstract}
Copyright: (C) HISPANIA NOVA es una revista debidamente registrada, con ISSN 1138-7319 y Depósito Legal M 9472-1998. Los textos publicados están -si no se indica lo contrario- bajo una licencia Reconocimiento-Sin obras derivadas 3.0 España de Creative Commons. Puede copiarlos, distribuirlos y comunicarlos públicamente siempre que cite su autor y la revista y la institución que los publica y no haga con ellos obras derivadas. La licencia completa se puede consultar en: http://creativecommons.org/licenses/by-nd/3.0/es/deed.es
\end{abstract}

\begin{abstract}
Resumen: Las relaciones entre los dos grandes sindicatos en España fluctuaron durante la transición democrática en función de varios factores políticos y de diversas estrategias sindicales, algunas de ellas fundamentadas en la aceptación o el rechazo de los pactos sociales. En el año 1982, la competencia por el voto obrero en las elecciones sindicales fue otro factor que enturbió las relaciones entre UGT y CCOO, dando lugar a una agria polémica sobre las fechas de cómputo electoral, con acusaciones de fraude, y con la negativa de CCOO de reconocer la victoria de UGT. La salida de este ambiente de confrontación fue una sorprendente apuesta de CCOO por la unidad sindical.
\end{abstract}

Palabras clave: Transición democrática, pactos sociales, elecciones sindicales, cómputo electoral, fraude electoral, unidad sindical.

\begin{abstract}
The relation between the two main trades unions in Spain fluctuated during democratic transition depending on several political factors and different unions strategies, some of them based on the acceptance or the rejection of the social agreements. In the year 1982, the competition for the workers vote in unions elections was other factor that muddied the relation between UGT and $\mathrm{CCOO}$, causing a bitter controversy in relation to the dates of electoral counting, with accusations of fraud, and the denial of CCOO to recognize the victory of UGT. The way off this atmosphere of confrontation was a surprising commitment of CCOO for unions unity.
\end{abstract}

Keywords: Democratic transition, social agreements, unions elections, electoral counting, electoral fraud, unions unity. 


\section{INTRODUCCIÓN}

Sobre las elecciones sindicales de 1982 existe un estudio sociológico que se basa en los datos del IMAC y en encuestas realizadas entre los votantes de los diferentes sindicatos. El mantenimiento del voto a un determinado sindicato o el cambio de voto hacia otra opción sindical es analizado en esta obra, aunque con una explicación limitada a unas pocas preguntas y respuestas de las encuestas realizadas. Los trabajadores que mantuvieron el voto al mismo sindicato en 1980 y en 1982 lo hicieron por ser un negociador eficaz, por la confianza en sus líderes o por la ideología de dicho sindicato y los que cambiaron el voto lo hicieron por cuestiones como la eficacia del nuevo sindicato en general o por la eficacia de ese sindicato en su empresa ${ }^{1}$. El estudio de los votantes, o sea la base trabajadora, debería ser una investigación complementaria a la nuestra, dado que este artículo va a centrarse en las estrategias de las direcciones de UGT y CCOO para obtener la victoria en las elecciones sindicales de 1982. En primer lugar, debemos conocer entorno sindical y el entorno político inmediatamente anterior a estas elecciones sindicales, es decir el entorno de la transición democrática.

\section{ENTORNO SINDICAL Y PACTOS SOCIALES}

Tras la muerte de Franco y con el segundo gobierno del Rey Juan Carlos I, presidido por Adolfo Suárez, tuvieron lugar las primeras elecciones democráticas en 1977. La etapa del consenso nació durante la negociación de la Constitución de 1978. En esta etapa se produjeron los primeros pactos sociales ${ }^{2}$. Aunque no son los únicos factores a tener en cuenta, los pactos sociales incidieron en la fluctuación de las relaciones entre los dos grandes sindicatos de clase. El primero de estos pactos sociales fueron los Pactos de la Moncloa. Este pacto fue suscrito por los principales partidos

\footnotetext{
${ }^{1}$ Francisco José, Navarro Botella. Las elecciones sindicales 1982. (Madrid: Fundación Friedrich Ebert, 1983). pp. 42-48.

2 Jorge de Esteban, "El proceso constituyente español, 1977-78", ed. por José Félix Tezanos, Ramón Cotarelo \& Andrés de Blas, La transición democrática española, (Madrid: Editorial Sistema, 1989), 275316.
} 
políticos en octubre de 1977 y fue aceptado por CCOO, a pesar de no haber participado. UGT le dio un no con reparos a este pacto, pero también acabó aceptándolo ${ }^{3}$. Un poco después tienen lugar las primeras elecciones sindicales, concretamente entre el 16 de enero y el 6 de febrero de $1978^{4}$. Los resultados de estas elecciones sindicales, según fuentes del Ministerio de Trabajo, fueron de un $21.69 \%$ para UGT, un $34.45 \%$ para CCOO, un $3.87 \%$ para USO y un $0.99 \%$ para ELA-STV 5 .

En 1979 no se consiguió ningún pacto social y hubo una subida salarial del 13\%, impuesta por Real Decreto, lo cual llevó a una fuerte conflictividad con el número más elevado de huelgas de la transición ${ }^{6}$. Quizás influyó en la falta de acuerdo la cercanía de las elecciones generales. Estas elecciones supusieron una frustración para la familia socialista, pues volvió a ganarlas la UCD. Tras ellas, UGT respondió al principio con dureza y con la unidad de acción con CCOO. Esta estrategia duró poco y fue sustituida mediante una serie de pactos con los empresarios de la CEOE, que preferían la moderación de UGT. Por contra al gobierno centrista le interesaba debilitar al PSOE y fortalecer a $\mathrm{CCOO}^{7}$.

Es necesario conocer que UGT y CCOO mantenían un enfrentamiento por la primacía de los comités de empresa (que apoyaba CCOO) o de las secciones sindicales (por las que apostaba UGT). Ello se debía a la debilidad de UGT, que durante su XL Congresos en 1976 solo contaba con unos siete mil afiliados ${ }^{8}$. Por tanto, UGT apostaba por fortalecer las estructuras sindicales y en ningún caso diluir la frontera entre afiliado y no afiliado. UGT tampoco fomentaba el sindicalismo asambleario, ni las estructuras

\footnotetext{
3 Álvaro Soto Carmona, "Comisiones Obreras en la transición y consolidación democrática: De la asamblea de Barcelona a la huelga general del 14-D (1976-1988)", dir. por José Babiano \& David Ruiz, Historia de Comisiones Obreras (1958-1988), (Madrid: Siglo XXI de España Editores, 1994), 451-521. Ángel Zaragoza, Justo Domínguez, \& Salvador Giner, Pactos sociales, sindicatos y patronal en España, (Madrid: Siglo XXI de España Editores, 1990), pp. 25-26,77-83,147-149. José María Marín Arce, "Les organitzacions socials durant la Transició: Sindicats i patronal", ed. por Lluis Basset \& Pere Ysas, La configuració de la democràcia a Espanya, (Vic: Eumo Editorial. 2009), 93-139.

${ }^{4}$ Ángel Zaragoza, Pactos..., op. cit., pp. 77-83.

5 Holm-Detlev Köhler, El movimiento sindical en España: Transición democrática, regionalismo, modernización económica, (Madrid: Fundamentos, 1995). p.133.

${ }^{6}$ José María Marín Arce, La configuració..., op. cit., pp. 93-139.

${ }^{7}$ Ibídem. Pp. 93-139.

${ }^{8}$ Rubén Vega García, La reconstrucción del sindicalismo en democracia, 1976-1994. Historia de la UGT. Vol.6. $1^{\text {a }}$ ed. (Madrid: Siglo XXI de España Editores, 2011). pp. 1-13.
} 
comunes como los comités de empresa, sino que lo que pretendía era fortalecer sus secciones sindicales ${ }^{9}$.

Después de las elecciones sindicales de 1978 se produjo un acercamiento entre UGT y CCOO, que sirvió para moderar los motivos de discrepancias que hemos citado. El fruto de este acercamiento fue la colaboración en las Jornadas contra el paro, convocadas por la Confederación Europea de Sindicatos el 5 de abril de $1978^{10}$.

Gracias a estas posiciones de UGT y CEOE se firmó el 10 de julio de 1979 el $\mathrm{ABI}$, un acuerdo interconfederal que primó a las secciones sindicales frente a los comités de empresas, tal como venía aspirando UGT. Con ello se fortaleció este sindicato en detrimento de $\mathrm{CCOO}^{11}$. El siguiente acuerdo fue el AMI, firmado por UGT y la CEOE en enero de 1980, con una duración de dos años. Este acuerdo consiguió una subida salarial del $15.33 \%$, una cláusula de revisión a los seis meses y que la CEOE reconociera los derechos sindicales. Con este acuerdo UGT dejó de caer en el seguidismo de CCOO, tuvo una estrategia propia, y posiblemente ayudó al avance en votos de la UGT en las elecciones sindicales de $1980^{12}$.

CCOO, no incluido en estos pactos, luchó contra el Estatuto de los Trabajadores que impulsó el ABI. CCOO también intentó superar la subida salarial del AMI mediante la movilización, aunque sin éxito. Marcelino Camacho no tenía un buen concepto del AMI, al cual se refirió como una estrategia para que PSOE llegar al poder, acusando al gobierno y a los empresarios de dividir el movimiento sindical. Además, advirtió a UGT que con la firma de estos acuerdos estaba renunciando al sindicalismo de clase ${ }^{13}$. Frente a este discurso de Marcelino, Nicolás Redondo afirmaba que CCOO subordinaba su acción sindical a una estrategia política determinada (se sobreentiende la del PCE).

\footnotetext{
${ }^{9}$ Ibidem. pp. 17-22.

${ }^{10}$ José María Marín Arce, La configuració..., op. cit., pp. 93-139.

11 Ángel Zaragoza, Pactos..., op. cit., pp. 29-32,81-82,149-151. Rubén Vega García, La reconstrucción..., op. cit., pp. 79-81. José María Marín Arce, La configuració..., op. cit., pp. 93-139.

12 Ángel Zaragoza, Pactos..., op. cit., pp. 32-35,82-83,151-155. Rubén Vega García, La reconstrucción..., op. cit., pp. 82-103.

13 Ángel Zaragoza, Pactos..., op. cit., pp. 32-35,82-83,151-155. Rubén Vega García, La reconstrucción..., op. cit., pp. 82-103. Marcelino Camacho, Confieso que he luchado: Memorias. (Madrid: Temas de hoy, 1990). pp. 456-469.
} 
Después de estos dos acuerdos no sería posible una nueva etapa de dialogo hasta después de las elecciones sindicales de $1980^{14}$.

Es posible que estos pactos ayudaran a UGT a subir en votos en las elecciones sindicales de 1980, aunque no pudo alcanzar el primer puesto. Los resultados fueron 29.4\% de votos para UGT y un 31\% para CCOO, con lo cual UGT subió un 7.7\% y CCOO bajó un 3.5\%. USO aumentó desde el 3.9\% al 9.4\%, pero no consiguió llegar al $10 \%$ y por tanto no llegó a ser sindicato más representativo según lo estipulado en el Estatuto de los Trabajadores recientemente aprobado. ELA-STV pasa del 0.9\% al 2.2\% y llegó a ser el primer sindicato en Euskadi. INTG/CXTG llega al 1.2\% y pasó a ser la tercera fuerza en Galicia ${ }^{15}$.

Habría que remarcar en estas cifras que UGT solo se encontraba en 1980 a un $0.6 \%$ de CCOO. Encuestas anteriores a las elecciones daban una mayoría más amplia a CCOO, pero una vez que UGT explicó a los trabajadores lo conseguido gracias el AMI, pudo decantar el voto más a su favor ${ }^{16}$.

El último pacto durante el último gobierno de la UCD fue el ANE, también conocido como "el pacto del miedo", debido a que nació tras la intentona golpista del 23 de febrero de 1981. Este pacto fue suscrito el 9 de junio de 1981 entre CCOO, UGT, CEOE y el gobierno de Calvo Sotelo. El ANE consiguió una banda salarial entre el 9\% y el $11 \%$ y la promesa de creación por parte del gobierno de trescientos cincuenta mil puestos de trabajo entre otros acuerdos, así como dos clausulas secretas (ochocientos millones de pesetas a cuenta del patrimonio sindical y la aceptación de la contratación temporal por los sindicatos) ${ }^{17}$. El acuerdo fue incumplido por la CEOE, que en octubre de 1981 se retiró de la comisión de seguimiento e intentó dificultar la negociación colectiva. Probablemente los empresarios querían con ello retirar el apoyo a UCD y optar por la formación derechista Alianza Popular ${ }^{18}$.

\footnotetext{
14 José María Marín Arce: La configuració..., op. cit., pp. 93-139.

${ }^{15}$ Antonio Ojeda Avilés y Jesús Maetzu Gregorio de Tejada, "Elecciones a representantes de personal y promoción de los sindicatos más representativos en la ley 8/1980". Revista De Política Social n¹37, (1983): 251-301.

${ }^{16}$ Francisco José Botella. Elecciones sindicales 1980: Las expectativas sindicales de los trabajadores españoles. (Madrid: Fundación Friedrich Ebert, 1982). pp. 80-92.

17 Ángel Zaragoza, Pactos..., op. cit., pp. 32-35,82-83,151-155. Rubén Vega García, La reconstrucción..., op. cit., pp. 82-103.

${ }^{18}$ José María Marín Arce: La configuració..., op. cit., pp. 93-139.
} 
La firma del pacto fue aceptada por más de la mitad de los trabajadores, con mayor aceptación en UGT, que en CCOO. Aunque a la vez que se aceptaba la firma, los trabajadores eran escépticos respecto a su utilidad para solventar el problema del paro y tampoco creían que fuera cumplido por gobierno y empresarios ${ }^{19}$.

\section{ENTORNO POLÍTICO E IMPORTANCIA DE LAS ELECCIONES SINDICALES}

Desde las primeras elecciones sindicales de la España democrática existió una discrepancia entre el voto político y el sindical. El 45\% de los que votaron a CCOO en las primeras elecciones sindicales tras la muerte de Franco, habían votado antes PSOE en las elecciones generales de junio de 1977. Treglia considera que muchos trabajadores apoyaron a CCOO de forma utilitarista, pese a no ser comunistas ${ }^{20}$. En un estudio sociológico de 1982 el voto político coincide con el porcentaje de Treglia, dando unos resultados de que un $45.1 \%$ de los electores de CCOO votaron al PSOE y el $42.8 \%$ votaron al $\mathrm{PCE}^{21}$. Como hemos visto la primacía de CCOO respecto a UGT se redujo en las elecciones sindicales de 1980. En las siguientes elecciones sindicales de 1982 UGT buscaba superar en votos y delegados a CCOO . De esta forma pretendía pasar a ocupar el primer lugar que venía ocupando $\mathrm{CCOO}$, para así poder equilibrar la discrepancia entre voto político y voto sindical.

Aunque es conveniente delimitar el ámbito político y el sindical, no debemos obviar que en 1.982 se produjeron ambas elecciones y que, como veremos, es uno de los motivos que UGT esgrime para querer posponer las elecciones sindicales. Las elecciones generales fueron convocadas por el presidente del gobierno, Calvo Sotelo, el

\footnotetext{
${ }^{19}$ Francisco José Navarro Botella. Elecciones..., op. cit., pp. 169-185.

${ }^{20}$ Emanuele Treglia. Fuera de las catacumbas: La política del PCE y el movimiento obrero. Vol. 28. $1^{\mathrm{a}}$ ed. (Madrid: Eneida, 2012). pp. 363-365.

${ }^{21}$ Francisco José Navarro Botella. Las elecciones...op. cit., p. 36.
} 
27 de agosto de 1982, esgrimiendo la imposibilidad de nuevas alianzas de gobierno por el cambio de partido de diputados y senadores de la $\mathrm{UCD}^{22}$.

Las escisiones dentro de UCD y los cambios de partido de sus parlamentarios se produjeron por la crisis interna de esta formación política, la cual se remontan mucho más atrás. Tendríamos que retrotraernos, como mínimo, a la dimisión del predecesor de Calvo Sotelo y fundador de UCD, Adolfo Suárez. Terminada la etapa del consenso, ya en el segundo gobierno de Adolfo Suárez en 1979, según Carmen Molinero y Pérez Ysas se produjeron una serie de factores, entre los que se encontraban la crisis económica tras la segunda crisis del petróleo, la violencia terrorista, y la crisis interna de la UCD, y todos ellos llevaron a la dimisión de Adolfo Suárez el 29 de enero de $1981^{23}$. También sería necesario tener en cuenta como factor de esta crisis el intento unificador de Adolfo Suárez, lo cual despertó el recelo de los barones y figuras preeminentes del partido $^{24}$. En opinión de Paul Preston nos encontraríamos con un Adolfo Suárez exhausto física y psicológicamente, que consideraba que si ganaba el II Congreso de UCD frente a los críticos solo le proporcionaría cinco o seis meses de respiro. Todo ello bajo la presión de una intervención militar en la política ${ }^{25}$.

Tras la dimisión de Adolfo Suárez, el II Congreso de UCD separó la función de presidente del partido y la de presidente del gobierno. Para la Presidencia del Gobierno se propuso al Congreso de los Diputados a Calvo Sotelo, que en primera votación no fue elegido al solo obtener 169 votos. En la siguiente sesión se produjo la intentona golpista del 23 de febrero de 1981, y tras el fracaso de esta intentona Calvo Sotelo recibió 186 votos y abrió otra etapa de consenso con la oposición tanto en economía, como en política autonómica. Este consenso solo se rompió en política exterior y defensa por la entrada en la OTAN ${ }^{26}$. Durante el gobierno de Calvo Sotelo, la postura del PSOE fue no

\footnotetext{
22 "Para agotar la actual legislatura el gobierno se vería obligado a entrar en pactos difíciles y artificiales.", $A B C, 28-08-1982$, p. 9.

${ }^{23}$ Carmen Molinero Ruiz, \& Pere Ysàs. “IX. La consolidación de la democracia, 1979-1982.”, ed. por José María Marín Arce, Pere Ysàs \& Carmen Molinero Ruiz, Historia política de España, 1939-2000. (Madrid: Ediciones Istmo, 2001), 227-320.

${ }^{24}$ Juan Antonio Andrade Blanco. El PCE y el PSOE en (la) transición: La evolución ideológica de la izquierda durante el proceso de cambio político. (Madrid: Siglo XXI de España Editores, 2012). pp. 384387.

${ }^{25}$ Paul Preston. El triunfo de la democracia en España, 1969-1982. (Barcelona: Plaza y Janés, 1986). pp. 215-251.

${ }^{26}$ Carme Molinero Ruiz, La consolidación..., op. cit., pp. 227-320.
} 
solo de consenso, sino incluso de buena disposición para formar parte de una coalición que solventara la crisis, aunque Calvo Sotelo rechazó la oferta socialista y continuó gobernando solo. ${ }^{27}$

Otros problemas debilitaban a UCD, entre ellos la falta de carisma de Calvo Sotelo y un cierto giro a la derecha del gobierno que dejaba el espacio de centro libre ${ }^{28}$. También continuaron los rumores de "solución armada" y la falta de iniciativa y dirección ${ }^{29}$. Por último, referir la agravación de la crisis interna cada vez mayor de la UCD. Entre los factores de esta crisis interna, según Carlos Huneeus, se encontraba el conflicto por la ley de divorcio entre los socialdemócratas y democristianos que componían UCD, las derrotas electorales en Galicia (octubre de 1981) y Andalucía (mayo de 1982), y el distanciamiento de los empresarios de la CEOE debido a las políticas económicas de ministros socialdemócratas de UCD. Todo ello culminaría en una desintegración mediante la escisión de los democristianos de Oscar Alzaga, la de los socialdemócratas de Fernández Ordoñez y la del propio fundador Adolfo Suárez, que creó el CDS. Este goteo de deserciones llevaría al adelanto electoral el 28 octubre de 1982 y a la retirada de Calvo Sotelo, que dejaría la candidatura a la presidencia del gobierno por UCD en manos de Landelino Lavilla ${ }^{30}$.

Si la situación de la UCD era crítica, no menos lo era la del PCE. Tras las primeras elecciones de 1977, durante los Pactos de la Moncloa y la negociación de la Constitución se impuso en el PCE la línea moderada eurocomunista y la estrategia de un gobierno de concentración con el objetivo evitar un golpe involucionista, aprobar el texto constitucional, solucionar el problema autonómico y dar respuesta a la crisis económica. La UCD no permitió este gobierno de concentración. Ante esta negativa el PCE quiso, como mínimo, impedir que la situación económica comprometiera la transición política. Los Pactos de la Moncloa sirvieron de sucedáneo al deseado gobierno de concentración y el PCE los promocionó. Es decir, el PCE defendió unos pactos que conllevaban medidas impopulares de congelación de salarios, contención del gasto público, e incluso la contención del sindicato CCOO. Otro sucedáneo fue la

\footnotetext{
${ }^{27}$ Paul Preston, El triunfo..., op. cit., pp. 215-251.

${ }^{28}$ Juan Antonio Andrade Blanco, El PCE..., op. cit., pp. 384-387.

${ }^{29}$ Paul Preston, La consolidación..., op. cit., pp. 215-251.

${ }^{30}$ Carlos Huneeus Madge. La Unión del Centro Democrático y la transición a la democracia en España (1st ed.). (Madrid: Siglo XXI de España Editores, 1985). pp. 306-413.
} 
negociación constitucional, aunque en este caso el PCE fue eclipsado por la negociación paralela del texto por Alfonso Guerra y Abril Martorell. Toda esta situación de acuerdos y consensos produjeron en abril de 1978 un IX Congreso del PCE en calma, incluso sirvió para frenar una huelga general por parte de $\mathrm{CCOO}^{31}$.

Pero a partir de 1979 la dinámica del consenso se rompió, dado que la crisis económica estaba un poco más encauzada y la Constitución ya se había aprobado. Superados estas grandes cuestiones, el PSOE se lanzó a una oposición sin ambages, incluida la Moción de Censura en 1980. En esta nueva etapa de mayor confrontación la política de concentración del PCE había dejado de tener sentido. Mientras tanto, en lo interno el PCE intentaba una homogenización ideológica que solo sirvió para desatar fuerzas centrifugas que llevarían en 1982 a su autoliquidación ${ }^{32}$. Además, la militancia del PCE, tal como observó Paul Preston, se desesperaba ante la imposición de la caduca dirección burocrática que Santiago Carrillo trajo de París en 1977, lo cual llevó a una incesante pérdida de militantes ${ }^{33}$.

Andrade se detiene más que Paul Preston en los diferentes conflictos internos que llevaron a esta situación en 1982, detallando como en enero de 1981 se celebró el V Congreso del PSUC en el cual se conjugaron la tendencia leninista y la prosoviética para rechazar la línea ideológica eurocomunista y reemplazar a la dirección catalana. Esta nueva dirección del PSUC formada por leninistas y prosoviéticos duró poco y los leninistas se inclinaron hacia los eurocomunistas, recuperando en mayo dicha denominación. Ante esta situación los prosoviéticos se escindieron del PSUC y crearon un nuevo partido, el PCC, arrastrando un buen número de militantes a sus filas ${ }^{34}$.

El siguiente conflicto se produce en Euskadi, donde la facción soberanista del EPK apostaba por la convergencia con Euskadiko Ezquerra. Al intentar llevar esta unificación de dos partidos a sus últimas consecuencias significó la expulsión del sector por la dirección del $\mathrm{PCE}^{35}$.

El último conflicto se visualizó en el X Congreso del PCE de julio de 1981 y supuso el fin de la cohesión interna por la división entre oficialistas, renovadores y

\footnotetext{
31 Juan Antonio Andrade Blanco, El PCE..., op. cit., pp. 55-86.

32 Juan Antonio Andrade Blanco, El PCE..., op. cit., pp. 357-361.

${ }^{33}$ Paul Preston, La consolidación..., op. cit., Pp. 215-251.

${ }^{34}$ Juan Antonio Andrade Blanco, El PCE..., op. cit., pp. 368-384.

35 Juan Antonio Andrade Blanco, El PCE..., op. cit., pp. 368-384.
} 
prosoviéticos. Los oficialistas eran eurocomunistas convencidos y algunos ortodoxos, pero sujetos a la disciplina del partido. Los renovadores eran también eurocomunistas, pero pedían más democracia interna (fin del centralismo democrático, modelo federal y posibilidad de crear corrientes) y por último los prosoviéticos que representaban las viejas esencias y la fidelidad a la URSS. El oficialismo de Santiago Carrillo asestó un duro golpe a sus adversarios en el $\mathrm{X}$ Congreso y abrió un posterior proceso de depuración interna ${ }^{36}$.

Con estos conflictos se comunicó a la sociedad una imagen de partido en quiebra, se añadía a ello la interpretación que para los votantes tenía el eurocomunismo, los votantes lo veían como una justificación de la estrategia de respaldo íntegro a la Constitución y de la dura salida de la crisis de los Pactos de la Moncloa. El cambio de estrategia en 1982 buscando la unidad de la izquierda solo fue visualizado como una manifestación de la desesperación. Todo ello llevó a la catástrofe electoral de octubre de $1982^{37}$.

Con la UCD y el PCE en crisis y con una derecha que no crece lo suficiente para llegar al poder, el partido que se encontraba en mejores condiciones para ganar las elecciones era el PSOE. El partido en 1979 había superado la polémica sobre el marxismo, la cual comenzó con declaraciones públicas de Felipe González a los medios de comunicación en mayo de 1978 a favor de eliminar todas las referencias al marxismo. Los críticos internos se tuvieron que enfrentar a la contradicción de seguir manteniendo el marxismo, pero a la vez aceptar a los líderes que se oponían al marxismo en la ejecutiva ${ }^{38}$. Los críticos cometieron el error de no dar más peso a las bases y fueron incapaces de plantear una alternativa a la ejecutiva. Así el XXVIII Congreso terminó sin ejecutiva y con una gestora copada por los felipistas, la cual llevó a un congreso extraordinario. En este congreso extraordinario de septiembre de 1979, se dejó al marxismo solo como un instrumento teórico, pero asumiendo otras aportaciones marxistas y no marxistas. La nueva ejecutiva era totalmente felipista y volvió a reelegir a Felipe González como Secretario General ${ }^{39}$.

\footnotetext{
${ }^{36}$ Ibidem. pp. 368-384.

${ }^{37}$ Ibídem. pp. 368-384.

${ }^{38}$ Richard Gillespie. Historia del Partido Socialista Obrero Español. (Madrid: Alianza, 1991). pp. 351357.

${ }^{39}$ Richard Gillespie, Historia..., op. cit., pp. 358-369.
} 
Tras la fallida moción de censura a Adolfo Suárez, se visualizaría al PSOE como alternativa de Gobierno. Alternativa reforzada por el nuevo consenso y concertación que ya hemos referido más arriba tras la intentona de golpe de estado de 1981. Concertación que no fue reciproca por parte del presidente Calvo Sotelo, dado que introdujo a España en la OTAN solo con sus aliados parlamentarios de centroderecha, sin convocar un Referéndum, como pedía el PSOE $^{40}$.

En octubre de 1981, el XXIX Congreso del PSOE dio muestras de moderación y uniformidad a diferencia de las referidas crisis de UCD y PCE. Quizás fue una uniformidad demasiado embarazosa, donde ni siquiera hubo representación de la izquierda del partido. Era una uniformidad con votaciones casi estalinistas, culto a la personalidad, disciplina rígida y prohibición de tendencias. Ideológicamente se rindió homenaje al viejo programa máximo, pero en realidad el partido solo trataba de edificar una nueva sociedad en medio de la convivencia pacífica de todos los ciudadanos de España. Incluso el programa económico se dejó para después del Congreso en manos de un grupo de expertos. Tras este congreso el PSOE llegó a 1982 con una gran moderación y obtuvo una gran victoria en las elecciones andaluzas, e incluso el PSOE estaba bien visto por una cuarta parte de los empresarios y por la banca ${ }^{41}$.

En estas circunstancias tras el XXIX Congreso se visualiza un PSOE compacto, centralizado y bajo el poder del Secretario General, que apareció como el único partido con la fuerza y firmeza necesarias para enderezar la situación. En definitiva, el PSOE supo explotar la crisis terminal de UCD y ocupar el espacio político que esta fuerza había dejado vacío, subiéndose al carro de la moderación y la modernización ${ }^{42}$.

Por tanto, el PSOE, en el ámbito político, estaba en las mejores condiciones de ganar las elecciones generales, en un año en el que a la vez en el ámbito sindical estaban teniendo lugar otra competición electoral. Competición electoral sindical, que como hemos observado, partieron de un periodo de distención entre los dos grandes sindicatos, debido al ANE.

Intentaré demostrar en este artículo que estas elecciones sindicales volverían a enturbiar las relaciones entre ambos sindicatos. Unas elecciones sindicales de especial

\footnotetext{
${ }^{40}$ Ibídem. Pp. 369-373.

${ }^{41}$ Richard Gillespie, Historia..., op. cit., pp. 373-379.

42 Juan Antonio Andrade Blanco, El PCE..., op. cit., pp. 384-387.
} 
trascendencia, dado que la familia socialista aspiraba a que el triunfo del PSOE en las elecciones generales fuera acompañado de un triunfo de UGT en las elecciones sindicales, para intentar asemejar el voto sindical y el voto político, que como hemos visto eran discordantes. Se quería corregir que mientras el PCE iba hacia la debacle electoral, el sindicato CCOO siguiera manteniendo una gran fuerza en el ámbito sindical, es decir se aspiraba a que UGT superara ampliamente a CCOO.

Es imprescindible dejar claro en este artículo también que UGT ganó las elecciones, refutando varias afirmaciones de $\mathrm{CCOO}$ y de los órganos de expresión próximos a $\mathrm{CCOO}$ en contrario. Por último, este artículo también aspira a buscar las motivaciones por la que volvió a reaparecer la propuesta de unidad sindical de CCOO de finales de 1982 (que ya había sido formulada en anteriores etapas históricas).

\section{LAS PRIMERAS REUNIONES PREPARATORIAS DE LAS ELECCIONES SINDICALES DE 1982}

Como hemos analizado se partía de una situación de distención entre ambos sindicatos después del ANE, pero esto comenzaría a cambiar con la convocatoria de las elecciones sindicales. La primera vez que se planteó la cuestión fue en el Secretariado de CCOO del 16 de febrero de $1982^{43}$. En otro Secretariado, el 2 de marzo, se optó por ceñirse a los dos años que marca la ley ${ }^{44}$. En la Ejecutiva Confederal del 16 de marzo se marcaron las líneas globales: Cumplir con la ley e intentar llegar a un calendario de consenso con UGT. Los detalles del procedimiento electoral se dejarían para un Consejo Confederal en mayo ${ }^{45}$.

\footnotetext{
${ }^{43}$ Acta de la reunión del Secretariado Confederal del día 16 de febrero de 1982. Punto II. Elecciones Sindicales, Archivo de Historia del Trabajo-Fundación $1^{\circ}$ de Mayo (en adelante AHT-FPM), Subfondo Secretariado Confederal de Comisiones Obreras, Signatura 004/020.

${ }^{44}$ Acta de la reunión del Secretariado Confederal del día 2 de marzo de 1982. Punto I. Elecciones Sindicales, Archivo Histórico de Comisiones Obreras de Andalucía. (en adelante AHCCOO-A), Comisiones Obreras de Andalucía, Caja 1.

${ }^{45}$ Acta de la reunión ordinaria de la Comisión Ejecutiva Confederal del día 16/03/82. Punto I. Elecciones Sindicales, AHCCOO-A, Comisiones Obreras de Andalucía, Caja 233.
} 
UGT también comenzó a tratar el tema en la Comisión Ejecutiva Confederal del 16 de febrero, en la cual ya se conocía la postura de CCOO de ceñirse a los plazos ${ }^{46}$. El 9 de marzo ese mismo órgano intentó tomar medidas para retrasar el proceso electoral, algunas de ellas parlamentarias a través del PSOE y otras con la CEOE ${ }^{47}$. El 16 de marzo se propuso sondear al gobierno de UCD y al sindicato nacionalista vasco ELASTV para el mismo objetivo ${ }^{48}$. En el Comité Confederal del 26 y 27 de marzo se decidió pedir una prórroga electoral ${ }^{49}$. Los motivos para pedir una prórroga eran que el organismo de control (IMAC) no estaba desarrollado en todas las provincias y que la posible coincidencia con las elecciones generales no iba a permitir la visibilidad de las elecciones sindicales ${ }^{50}$.

En prensa las primeras noticias sobre elecciones sindicales no se produjeron hasta abril y mayo. Así el diario El País informó el 29 de abril sobre las elecciones para delegados sindicales de Radio Televisión Española (RTVE) ${ }^{51}$. El 1 de junio $A B C$ hablaba de forma general sobre las elecciones sindicales, aclarando que el pistoletazo de salida se produjo el 15 de marzo y que culminarían el 31 de diciembre, aunque la mayor parte de las votaciones se realizarían en el tercer trimestre del año ${ }^{52}$.

El Socialista, órgano oficial del PSOE, se refirió a las elecciones sindicales a mediados de mayo, con las victorias de UGT en SEAT y RTVE. Para la revista todo apuntaba a una victoria de UGT. A la vez mencionaba la posición de Nicolás Redondo, que era partidario de retrasarlas por la posible coincidencia con las elecciones generales $^{53}$.

\footnotetext{
${ }^{46}$ Acta de la Reunión de la Comisión Ejecutiva Confederal del 16.02.82. Punto 2.2. Reunión con CCOO. Elecciones Sindicales, Archivo de la Fundación Largo Caballero (en adelante AFFLC), Fondo UGT, Sig. 002560-001 a 002564-003.

${ }^{47}$ Acta de la Reunión de la Comisión Ejecutiva Confederal del 09.03.82. Punto III. Elecciones Sindicales, AFFLC, Fondo UGT, Sig. 002560-001 a 002564-003.

${ }^{48}$ Acta de la Reunión de la Comisión Ejecutiva Confederal del 16.03.82. Punto II. Elecciones Sindicales, AFFLC, Fondo UGT, Sig. 002560-001 a 002564-003.

${ }^{49}$ Acta de la Reunión del $5^{\circ}$ Comité Confederal de UGT celebrado en Madrid el 26 y 27 de marzo de 1982. Punto 9.4. Elecciones Sindicales, AFFLC, Fondo UGT, Comisión Ejecutiva Confederal, Sig. 002604-007 a 002604-011.

50 "Elecciones sindicales. Un retraso necesario." (editorial), Unión, nº18, 01-04-1982, p.2.

51 "Hoy se celebran elecciones sindicales en RTVE.", El País, 29-04-1982.

52 "Están en marcha las terceras elecciones sindicales españolas.", ABC de Sevilla, 01-06-1982, p. 30.

53 “Victoria electoral de UGT en SEAT y RTVE.”, El Socialista, n²57, del 12-05-1982 al 18-05-1982. p. 0 .
} 
Por todo ello se puede concluir que los dos principales sindicatos no empezaron a organizarse y considerar que se encontraban en año electoral hasta principios o mediados de marzo de 1982 y la discrepancia en esta etapa era, principalmente, sobre si celebrarlas o retrasarlas.

\section{EL DOBLE JUEGO DE UGT}

La preparación de las elecciones continuó. El 11 y 12 de mayo la Ejecutiva de CCOO llevó al Consejo Confederal un documento de análisis denominado "Guion para el Debate" (aunque fechado en marzo), que fue aprobado por 92 votos a favor y solo 4 abstenciones. En dicho documento se realizaba un análisis de anteriores elecciones sindicales, la actitud de la CEOE, el gobierno y la UGT (su petición de aplazamiento) ante ellas, así como las perspectivas electorales ${ }^{54}$. La reunión del Consejo, en torno al referido documento tuvo una función informativa y organizativa, se explicó que hasta septiembre habría un goteo de elecciones en las empresas, a medida que los comités caducaran, pero que el grueso de las elecciones se produciría a partir de septiembre ${ }^{55}$. Tras esta reunión CCOO comunicó a la prensa que no quería retrasar las elecciones sindicales y las iba a compaginar con movilizaciones ${ }^{56}$.

Por las mismas fechas de mayo, Mundo Obrero suministró datos electorales de la empresa Bazán y datos de incremento de afiliación de CCOO en Renfe, en el sector de la construcción, en el sector de la madera y en algunas regiones ${ }^{57}$. Desde esta revista se comenzó a contabilizar victorias de CCOO en grandes empresas desde septiembre de $1981^{58}$.

\footnotetext{
${ }^{54}$ Acta del Consejo Confederal del 11 y 12 de mayo de 1982. Punto II: Plan de elecciones sindicales, AHCCOO-A, Comisiones Obreras de Andalucía, Caja 132.

${ }^{55}$ Guion para el debate sobre elecciones sindicales, AHCCOO-A, Comisiones Obreras de Andalucía, Caja 132.

56 “CCOO insiste en no aplazar las elecciones sindicales.", El País, 13-05-1982.

57 “CCOO mejora su imagen ante el país.”, Mundo Obrero, Año IV, nº174, del 30-04-1982 al 06-05-1982, pp. 22-23.

58 "Elecciones en empresas de más de mil trabajadores.", Mundo Obrero, Año IV, nº178, del 27-05-1982 al 03-06-1982, p. 20.
} 
En el Secretariado de CCOO el tema de las elecciones sindicales no se volvió a tratar hasta el 22 de junio, con la queja de falta de resultados por parte del IMAC ${ }^{59}$. A mediados de julio se comenzó a preparar el programa y la campaña electoral, pero no fue hasta septiembre cuando se ultimó el programa. Marcelino Camacho apostó por centrarse en las elecciones sindicales más que en las elecciones políticas, pues consideraba que el PSOE iba a ganar con un programa "supermoderado"60.

UGT realizó un doble juego que consistió en mover fichas para conseguir un retraso electoral a través de la vía parlamentaria, pero a la vez se implicó en el proceso electoral y fue ganando elecciones en empresas. En el interno, UGT decidió organizar los Comités Electorales para el verano y se emplazó a acordar en septiembre, con CCOO, el periodo de cómputo de las elecciones. Del acta de la Ejecutiva Confederal podemos deducir que UGT estaba más retrasada en la organización de las elecciones sindicales que $\mathrm{CCOO}^{61}$.

La revista Unión de junio explicaba los motivos por los cuales UGT quería retrasar las elecciones, entre los que se encontraba la insuficiencia y precariedad de los IMAC provinciales, la inoportunidad de la coincidencia con las elecciones políticas, la negociación colectiva en plenas elecciones o la necesidad de legislar para ampliar el periodo electoral a más de dos años. Pero en la revista también se asumía que UGT no iba a conseguir dicho retraso, y por tanto estaba trabajando en ganar las elecciones, obteniendo triunfos en SEAT, Correos, TVE, Ensidesa, La Camocha o Renault ${ }^{62}$.

Observamos que a alturas de junio de 1982 todavía no existía un claro enfrentamiento entre los dos sindicatos mayoritarios. Las discrepancias respecto al aplazamiento electoral o las críticas a la moderación del PSOE no pueden calificarse de enfrentamiento abierto entre sindicatos, máxime cuando a pesar de estas discrepancias, ambos sindicatos siguen abiertos al consenso.

\footnotetext{
59 Acta de la reunión ordinaria del Secretariado Confederal del día 22/06/82. Punto I. Elecciones Sindicales, AHCCOO-A, Comisiones Obreras de Andalucía, Caja 1.

60 Acta de la reunión ordinaria del Secretariado Confederal del día 07/09/82. Punto II. lecciones Sindicales, AHCCOO-A, Comisiones Obreras de Andalucía, Caja 1.

${ }^{61}$ Acta de la Reunión de la Comisión Ejecutiva Confederal del 27.04.82. Punto VI. Elecciones Sindicales, AFFLC, Fondo UGT, Sig. 002560-001 a 002564-003.

62 “Ante las elecciones sindicales.”, Unión, n²3, 18-06-1982, pp. 1-2.
} 


\section{ENFRENTAMIENTO SINDICAL, LA AYUDA SOCIALISTA A UGT, POLÉMICA DE FECHAS Y DATOS ELECTORALES}

Durante el verano comenzaron los enfrentamientos entre UGT y CCOO. La primera polémica surgió por el apoyo de UGT al futuro gobierno socialista, que parecía contrastar con la independencia de Comisiones. El sindicato CCOO aseguraba en junio que solo apoyaría al PSOE si favorecía a los trabajadores ${ }^{63}$. La segunda polémica se produjo por la dimisión de Marcelino Camacho del Congreso de los Diputados y de la Ejecutiva del PCE. Marcelino Camacho justificó esta dimisión para salvaguardar la independencia de CCOO y para mantener su papel arbitral como Secretario General de $\mathrm{CCOO}^{64}$. Nicolás Redondo, por el contrario, achacó la dimisión a la guerra interna del PCE y afirmó que Marcelino Camacho estaba siendo manejado por la tendencia estalinista. Respecto al primera polémica, Nicolás Redondo no comprendía que se atacara a un posible gobierno progresista del PSOE, y afirmó que UGT seguiría manteniendo su autonomía ${ }^{65}$.

Mientras tanto continuaba la preparación de las elecciones con el recurso de UGT a la familia socialista, pidiendo al PSOE realizar visitas conjuntas a los territorios $^{66}$. Las visitas supusieron solo los inicios de la campaña, pues la propaganda electoral no estaría lista hasta septiembre ${ }^{67}$.

Resulta clarificadora una entrevista a Antón Saracibar en El Socialista respecto a las aspiraciones del sindicato. La revista también da a conocer algunos datos favorables de las elecciones en empresas mayores de 250 trabajadores. Antón Saracibar aclaró que el sindicato UGT aspiraba a incluir a los independientes en sus filas y a la hegemonía sindical con un $40 \%$ de los delegados y un $10 \%$ de la representatividad. Antón Saracibar volvió a pedir el retraso de las elecciones sindicales, en base a la coincidencia con las elecciones generales y con la negociación colectiva de 1983. Respecto al cómputo

\footnotetext{
63 "Marcelino Camacho acusa a UGT de capitalizar el voto y la imagen del PSOE.", El País, 17-06-1982.

64 “Política. Comité Central del PCE.”, Mundo Obrero, Año IV, del 18-06 al 24-06-1982. p. 13.

65 “Polémica entre UGT y CCOO.”, El Socialista, n²63, del 23-06 al 30-06-1982. pp. 34-36.

${ }^{66}$ Acta de la Reunión de la Comisión Ejecutiva Confederal del 05.07.82. Punto III. Elecciones sindicales, AFFLC, Fondo UGT, Sig. 002560-001 a 002564-003.

${ }^{67}$ Acta de la Reunión de la Comisión Ejecutiva Confederal del 20.07.82. Punto IV. Elecciones sindicales, AFFLC, Fondo UGT, Sig. 002560-001 a 002564-003.
} 
electoral, es partidario de iniciarlo 15 de marzo de 1982 y consideraba la fecha del 1 de enero de 1982, que quería CCOO, como algo muy difuminado ${ }^{68}$.

A finales de julio, en el VI Comité Confederal de UGT, se repartió una guía electoral, que fue enmendada en dicha reunión y se indicó a los miembros del Comité que la guía debía adaptarse y hacerse flexible a cada empresa. Se solicitó que estas reflexiones se llevaran a todos los puntos de la organización en el país, así como un gran esfuerzo y agilidad en las elecciones sindicales. Fue el punto de partida para poner a trabajar la organización en el grueso de las elecciones sindicales ${ }^{69}$. El lema elegido por UGT para estas elecciones fue: "La fuerza sindical para el cambio", en clara referencia al posible cambio político que se intuía se iba a producir en el país de mano del PSOE, la fuerza política hermana ${ }^{70}$.

En junio CCOO también estaba en marcha y difundió datos parciales sobre su victoria en grandes empresas del metal de más de mil trabajadores ${ }^{71}$. Para ganar las elecciones sindicales CCOO se apoyaba en un proyecto movilizador y de transformación social: El Plan de Solidaridad Nacional. Mediante este plan, la movilización y participación de todos los trabajadores construirían una fórmula de apoyo al nuevo gobierno frente a los intereses oligárquicos y frente a las vacilaciones dentro de las propias filas socialistas ${ }^{72}$.

Como hemos observado cada sindicato suministraba datos electorales que le favorecían, aunque el IMAC de forma oficial no daba por válidos estos resultados que difundían los sindicatos y se proclamaba a sí mismo como el único órgano que puede dar resultados oficiales ${ }^{73}$. El diario $A B C$ si difundió unos datos del IMAC favorables para CCOO, aunque contabilizados desde enero de $1982^{74}$.

\footnotetext{
68 "UGT por la definitiva clarificación.", El Socialista, n²70, del 11-08-1982 al 17-08-1982. pp. 32-34.

${ }^{69}$ Acta de la Reunión del Comité Confederal del 27 y 28.07.82. Punto IV, AFFLC, Fondo UGT, Sig. 002605-001 a 002605-004.

70 “UGT la fuerza sindical para el cambio.", Unión, n²6, 01-08-1982, pp. 1-6.

71 “El ANE puede y debe cumplirse.”, Mundo Obrero, Año IV, nº182, del 25-06-1982 al 01-07-1982, pp. 20-21.

${ }^{72}$ Héctor Maravall, “Voto. ¿Útil a quién?”, Mundo Obrero, Año IV, del 09-07-1982 al 15-07-1982, pp. 20-21.

73 “Elecciones Sindicales.”, El País, 28-08-1982.

74 “CCOO va ganando las elecciones sindicales.”, $A B C, 27-08-1982$, p. 36.
} 


\section{LOS SINDICATOS ANTE LAS ELECCIONES GENERALES Y EL NUEVO GOBIERNO}

\section{La postura de CCOO sobre el cambio político}

E1 27 de agosto el presidente Calvo Sotelo convocó elecciones generales para el 28 de octubre de 1982. Ante esta convocatoria hay que tener en cuenta que CCOO se definía como sindicato sociopolítico, y por tanto mantenía sus propias propuestas para los trabajadores. Estas propuestas sociopolíticas de CCOO eran las mismas con las que se presentaba a las elecciones sindicales. A grandes rasgos CCOO apostaba por un plan de empleo, por una mayor protección al desempleo, por la reconversión industrial y reindustrialización, por la nacionalización del sector energético, por la reforma agraria, por la jornada de 35 horas, por la jubilación a los 60 años, la escolarización obligatoria hasta los 18 años, la reducción de horas extras y desaparición del pluriempleo, la revisión del Estatuto de los Trabajadores, por dar mayor poder a los comités de empresa, por la derogación de los decretos de contratación temporal, la defensa del poder adquisitivo de salarios y pensiones, vivienda para los trabajadores, apostaba por la paz, el desarme, y era contrario la OTAN. ${ }^{75}$ Estas propuestas alternativas de CCOO fueron presentadas el día 17 de septiembre al PCE y el 20 del mismo mes al PSOE ${ }^{76}$. A pesar de que el PCE fue el único que asumió íntegramente el programa de CCOO, el sindicato no pidió claramente el voto a ningún partido. Solo la Corriente Socialista Autogestionaria pidió el voto para el PSOE y una reunión de cuadros sindicales comunistas dijeron claramente que iban a trabajar a favor del voto al PCE y al PSUC ${ }^{77}$.

Tras el triunfo del PSOE, la postura de CCOO fue que apoyaría todos los cambios hacía delante del PSOE, considerando que tener el gobierno no es tener el poder, dado que seguían existiendo poderes fácticos que no habían cambiado de manos. Este apoyo a los pasos adelante del PSOE no implicaba que CCOO renunciara al derecho a la crítica constructiva. CCOO quería seguir siendo un sindicato independiente

\footnotetext{
75 Acta de la reunión del Consejo Confederal del día 09/09/1982. Acta y Documentos anexos. AHCCOOA, Comisiones Obreras de Andalucía. Caja 132.

76 "El programa del PCE no contempla la nacionalización de la banca privada y si los sectores básicos de la energía.", El País, 17-09-1982.

77 “Reunión de cuadros sindicales.”, Mundo Obrero, Del 01 al 07-09-1982, Año IV. pp. 23-24.
} 
que defendía a los trabajadores por encima de todo, y más teniendo en cuenta que temía que la UGT se subordinara al programa de gobierno del PSOE $^{78}$.

Marcelino Camacho consideraba insuficiente el programa del PSOE y se quejaba de la ley D'hont, por desfavorecer a otras minorías de izquierdas (en referencia al PCE), pero creía que había que forzar al PSOE, no al desgaste sino a la modificación de sus planteamientos. Creía Marcelino que UGT se encontraría frente a un programa moderado y limitado del PSOE. Debido a ello, Marcelino proclamaba que CCOO iba a luchar porque UGT no se llegara a transformar en un sindicato gubernamental y para que no fuera un freno para el cambio ${ }^{79}$.

\section{EI apoyo de UGT a su partido hermano}

En la Ejecutiva Confederal de UGT del 9 de septiembre de 1982 se informó por parte de Manuel Chaves que el PSOE había aceptado las aportaciones del sindicato socialista al programa electoral del partido ${ }^{80}$. El PSOE había asumido las propuestas de UGT, las cuales consistían en creación de empleo, ampliación de la cobertura a los parados, reparto racional de trabajo disponible, apoyo a los sindicatos, creación de un marco democrático de relaciones laborales, potenciación de la participación de los trabajadores en las instituciones y la empresa. Por ello UGT pidió a los trabajadores el voto para el PSOE, aunque aclaró que mantendría una actitud vigilante y crítica ante el nuevo gobierno socialista, y que continuaría con su capacidad reivindicativa ${ }^{81}$. El Comité Confederal Extraordinario de UGT del 2 de octubre de 1982 aprobó apoyar al PSOE y pedir el voto para este partido en las elecciones generales del 28 de octubre de

\footnotetext{
${ }^{78}$ Acta de la reunión de la Comisión Ejecutiva Confederal del día 31/10/1982. Punto I. Elecciones Generales. Informe anexo del Secretario General. AHCCOO-A, Comisiones Obreras de Andalucía. Caja 233.

79 “CCOO no quiere una UGT gubernamental.”, El País, 08-11-1982.

${ }^{80}$ Acta de la Reunión de la Comisión Ejecutiva Confederal del 21.09.82. Punto II.1. Programa de Gobierno PSOE. AFFLC. Fondo UGT. Sig. 002560-001 a 002564-003.

${ }^{81}$ Acta de la Reunión del Comité Confederal Extraordinario del 02.10.82. Documento anexo al acta sobre las Elecciones Generales. AFFLC. Fondo UGT. Sig. 002605-005.
} 
1982. El comunicado fue criticado internamente, pero estas críticas se solventarían incorporando algunas enmiendas de los $\operatorname{críticos}^{82}$.

Tras la victoria socialista UGT también realizó un análisis de los resultados electorales y las perspectivas que se abrían. UGT ratificó el apoyo al nuevo gobierno partiendo de la inclusión de las propuestas de la UGT en el programa socialista. Para UGT el PSOE había ganado gracias al voto obrero y realizó un llamamiento a este partido a no negociar el programa electoral con otros sectores ajenos a esta victoria. Para UGT había llegado la hora de pedir que se cumpliera dicho programa con celeridad. El cumplimiento del programa no era negociable, al tratarse de un compromiso con el pueblo ${ }^{83}$.

Respecto al papel de la UGT no debía quedarse en ser un interlocutor privilegiado con su partido hermano, debía de representar a los trabajadores y ser el vehículo de expresión de estos. El toque de atención era pertinente dado que si olvidan el papel de representantes de los trabajadores llevaría a que otros sindicatos ocuparan esa representación. En caso de que el gobierno no cumpliera el programa, no apoyara el sindicalismo o en caso de que UGT dejara de encauzar las reivindicaciones de los trabajadores sería malo para las dos fuerzas hermanas ${ }^{84}$.

Como vemos, por tanto, para ambos sindicatos era importante el triunfo electoral del PSOE en un año de elecciones sindicales. CCOO marcó distancias con el nuevo gobierno y su estrategia era la de vencer o de mantener una posición poderosa con el objetivo de girar la política económica del PSOE hacia posiciones más a la izquierda. Una amplia derrota en las elecciones sindicales no permitiría a CCOO este tipo de influencia en la política económica.

Por su parte UGT si estaba de acuerdo con el programa político de su partido hermano, dado que sus propuestas habían sido incluidas en el programa. Pero una vez que se había producido la victoria del PSOE dio el primer toque de atención para que el cumplimiento de este programa no sea negociable con otros sectores ajenos a los trabajadores. Con ello empezó a marcar una cierta autonomía respecto al PSOE.

\footnotetext{
${ }^{82}$ Acta de la Reunión del Comité Confederal Extraordinario del 02.10.82. Punto III .Elecciones Generales. AFFLC. Fondo UGT. Sig. 002605-005.

83 Acta de la Reunión del Comité Confederal del 4-5.12.82. Acta y Documentos aprobados. AFFLC. Fondo UGT. Sig. 002605-006.

${ }^{84}$ Acta de la Reunión del Comité Confederal del 4-5.12.82. Acta y Documentos aprobados. AFFLC. Fondo UGT. Sig. 002605-006.
} 
Posiblemente la defensa del trabajador, incluso empezando a marcar distancias con el partido hermano, podía dar confianza para ganar las elecciones sindicales, algo que en octubre de 1982 todavía no estaba del todo claro.

\section{LAS DOS ELECCIONES DE OTOÑO}

Tal como preveía UGT las elecciones políticas ocultaron las elecciones sindicales y ello se constataba en prensa y revistas. Mundo Obrero dedicaba casi toda la publicación a la convocatoria de elecciones generales, dejando solo un hueco para las elecciones sindicales, en donde informaban que un $34.59 \%$ de los delegados eran para CCOO y un $25.64 \%$ para UGT. Se decía en la revista que estos datos eran oficiales en la medida que habían sido facilitados por el Secretario General del IMAC, algo con lo que no estaba de acuerdo UGT, pues la publicación oficial debía ser posterior al 31 de diciembre de 1982. Mundo Obrero apostaba por contabilizar desde 1981 y tachaba de argumentos triviales el no querer reconocer estos resultados ${ }^{85}$. Además, la citada revista comenzó a hablar de fraude electoral y explicaba que CCOO llevó un notario a varias empresas para certificar que gente de UGT rellenaban un acta, tomaban firmas y fingía que se habían celebrado elecciones sindicales ${ }^{86}$.

Si las fechas y los datos electorales no estaban definidos, lo que si quedaba claro es que el grueso de las elecciones se realizaría a partir de septiembre. En el Secretariado de CCOO del 21 de septiembre se dieron instrucciones para poner a trabajar a toda la organización en las elecciones sindicales, las mismas instrucciones ponían en alerta sobre los datos del IMAC y se apostaba por contabilizar desde el 1 de enero, o en caso contrario se tomaría la decisión de activar el gabinete jurídico de $\mathrm{CCOO}^{87}$.

El Socialista también se centró en las elecciones políticas, pero en septiembre publicó datos de las elecciones sindicales recopilados por UGT, datos sobre los que se

\footnotetext{
85 “CCOO va ganando.”, Mundo Obrero, Año IV, nº192, del 03-09 al 09-09-1982, pp. 22-23.

86 "Fraude de UGT en algunas elecciones sindicales.", Mundo Obrero, Año IV, nº193, del 15-10 al 21-101982, p. 21 .

${ }^{87}$ Acta de la reunión ordinaria del Secretariado Confederal del día 21/09/82. Punto II. Información Elecciones Sindicales, AHCCOO-A, Comisiones Obreras de Andalucía, Caja 1.
} 
afirmaba que estaban contrastados con los IMAC provinciales, rechazando los de CCOO (provenientes del IMAC central) y los de Mundo Obrero. Exceptuando Euskadi y Cataluña, reflejaban que la UGT iba ganando por un $34.9 \%$, frente a un $34.7 \%$ de CCOO, estos datos estaban contabilizados desde el 15 de marzo de 1982 hasta el 25 de agosto de $1982^{88}$. A mediados de octubre volvió a dar datos, en este caso desde el 15 de marzo de 1982 hasta el 1 de octubre de 1982. Los resultados de El Socialista daban un 44.17\% para UGT y un $31.21 \%$ para CCOO, en base a un análisis de la UGT que reafirmaba el mantenimiento del voto de CCOO, y un aumento del voto de UGT por trasvase de votos de USO y de independientes ${ }^{89}$.

A fecha 9 de octubre la insistencia de CCOO en la ampliación del periodo se basaba en que gracias a esta ampliación iba ganando las elecciones, de otra forma la victoria sería de UGT. Según los apuntes de Eduardo Saborido esto se afirmó en la misma reunión del Secretariado de $\mathrm{CCOO}$ en la que se aprobó centrarse en las elecciones en Madrid, Barcelona, Vizcaya, Zaragoza, Sevilla y Valencia ${ }^{90}$.

En opinión del diario El País las polémicas sobre la fecha de inicio del cómputo, los resultados y los posibles fraudes hacían un flaco favor a la imagen de ambos sindicatos $^{91}$. Dicho diario detallaba todo tipo de irregularidades que el IMAC había dado orden de no contabilizar ${ }^{92}$. $A B C$ reflejaba el 3 de octubre que la central que apoyaba al PSOE encabezaba los resultados de las elecciones sindicales según el IMAC $^{93}$.

Al final del mandato de UCD se intentó negociar la regulación de las elecciones sindicales, pero sin decidir las fechas concretas de las mismas. Las posturas seguían enfrentadas, CCOO apostaba por contabilizar desde el 1 de enero de 1981 hasta el 31 de diciembre de 1982, mientras que UGT pedía que se contabilizara desde el 15 de marzo de 1982 hasta el 31 de marzo de 1982. En realidad, bajo los argumentos de cada central

\footnotetext{
88 “Primeros datos electorales: primeras ventajas de UGT.”, El Socialista, n²73, del 01-09-1982 al 07-091982, p. 43.

89 “UGT crece, CCOO se mantiene.”, El Socialista, n²79, del 13-10-1982 al 19-10-1982, p. 37.

${ }^{90}$ Acta de la reunión ordinaria del Secretariado Confederal del día 09/10/82. Punto 2. Elecciones Sindicales, Eduardo Saborido, apuntes anexos a dicha acta, AHCCOO-A, Comisiones Obreras de Andalucía, Caja 1.

${ }^{91}$ Rodolfo Serrano, "Las elecciones sindicales contra CCOO y UGT.”, El País, 13-10-1982.

92 "El IMAC dicta instrucciones para evitar la manipulación de los resultados de las elecciones sindicales.", El País, 23-10-1982.

93 “El Comité Confederal de UGT apoya el programa del PSOE.”, $A B C, 03-10-1982$, p. 59.
} 
se escondía el resultado favorable a una u otra central sindical ${ }^{94}$. A finales de octubre, el IMAC, todavía bajo el gobierno centrista, tomó la decisión de publicar resultados desde el 1 de enero de 1982 (decisión que el nuevo gobierno del PSOE rectificará). Hasta esa fecha el IMAC no había accedido a publicar resultados periódicamente para no influir en el resultado definitivo, los que he detallado más arriba eran extraoficiales ${ }^{95}$.

En el Consejo Confederal de CCOO del 31 de octubre, realizado principalmente para analizar el triunfo electoral del PSOE, también se trataron las elecciones sindicales en curso y se cuestionaron los datos del IMAC que estaba difundiendo UGT, rebatiéndolos con datos propios de $\mathrm{CCOO}$, en los cuales se afirmaba que estaban ganando las elecciones sindicales y se habló de enviar una carta explicando el fraude que se estaba difundiendo con la supuesta victoria de la $\mathrm{UGT}^{96}$. Este mismo informe se ratificó en el Consejo Confederal del 7 de noviembre ${ }^{97}$. En el Secretariado del día anterior a este Consejo se afirmó que CCOO iba ganando las elecciones sindicales por 1.2 puntos a la UGT, empezando a contar las mismas desde enero de 1981, mientras el IMAC decía que CCOO iba perdiendo frente a UGT (42.5\% frente a 35.3\%). Ante estos datos se decidió insistir en la postura de CCOO sobre los resultados, pidiendo una reunión urgente con el IMAC y denunciar mediante nota de prensa y en televisión estos resultados con los que no se estaba de acuerdo ${ }^{98}$. En el siguiente Secretariado de mediados de noviembre no se insistió en la polémica de datos, sino en el trabajo de campaña en las grandes zonas industriales donde se podían sacar más delegados ${ }^{99}$.

Mundo Obrero de noviembre solo dedicaba una pequeña separata interior a reafirmar el triunfo electoral de CCOO y a volver a denunciar casos de actas fraudulentas por parte de UGT, por ejemplo, la elección de un delegado fallecido meses

\footnotetext{
94 "La normativa electoral sindical, en el aire.", $A B C, 13-10-1982$, p. 52.

95 "El IMAC publicará el resultado de las elecciones sindicales celebradas desde el 1 de enero.", El País, 28-10-1982.

${ }^{96}$ Informe sobre elecciones politicas y sindicales. Anexo al acta de la Ejecutiva Confederal del 31/10/82, AHCCOO-A, Comisiones Obreras de Andalucía, Caja 233.

97 Acta del Consejo Confederal Extraordinario del 07.11.1982. Elecciones Políticas y Sindicales, AHCCOO-A, Comisiones Obreras de Andalucía, Caja 233.

${ }^{98}$ Acta de la reunión ordinaria del Secretariado Confederal del día 30/10/82 Punto 2.

Elecciones Sindicales, Eduardo Saborido, apuntes anexos a dicha acta, AHCCOO-A, Comisiones Obreras de Andalucía, Caja 1.

99 Acta de la reunión ordinaria del Secretariado Confederal del día 14/11/82. Punto 2. Elecciones sindicales, AHCCOO-A, Comisiones Obreras de Andalucía, Caja 1.
} 
antes. La revista afirmaba que CCOO iba ganando hasta el 27 de octubre, aunque solo aportaba datos de Cataluña, Andalucía, Madrid y Asturias ${ }^{100}$. En el siguiente número si aportaba datos de todo el país, asignando un 35.8\% para CCOO y un $33.5 \%$ de delegados para UGT. Mundo Obrero justificaba que sus datos contradijeran los del IMAC, porque en aquellos faltaban los datos del segundo semestre en Euskadi y Cataluña, así como los datos de 1981. Añadiendo todos estos datos de las actas entregadas por $\mathrm{CCOO}$ a fecha de 4 noviembre la victoria era de $\mathrm{CCOO}^{101}$. A final de mes Mundo Obrero se posicionaba a favor del cómputo electoral desde el año 1981 y expresaba los temores de que tanto al nuevo gobierno como a la patronal le interesara una victoria de UGT, sindicato que en opinión de la revista prefería desarrollar un sindicalismo de gestión a uno participativo. Este tipo de sindicalismo filtraba las peticiones de los trabajadores "las hacia digeribles" al gobierno ${ }^{102}$.

La visión contraria la encontramos en el órgano oficial de UGT, la revista Unión, que volvió a explicar la incoherencia de querer dar por validos resultados de 1981, en los cuales no existía el IMAC para contralar el proceso. Además, dichos resultados caducarían antes de que terminara el nuevo mandato. La revista apoyaba el 15 de marzo de 1982 como primera fecha para el inicio del cómputo y consideraba que no se debía denunciar fraudes en prensa, sino en el IMAC, dado que lo primero desprestigiaba al sindicalismo. E1 15 de octubre Unión desglosaba las victorias de UGT y afirmaba que seguía ganando las elecciones ${ }^{103}$.

A finales de noviembre el Consejo de Estado revitalizó la polémica sobre el periodo electoral al decidir que la fecha de inicio del cómputo electoral fuera el 1 de enero de 1981, coincidente con lo que solicitaba $\mathrm{CCOO}^{104}$. Frente a ello UGT continuó defendiendo la fecha inicio del 15 de marzo de 1982 y consideraba que la decisión del Consejo de Estado no era vinculante. CCOO afirmaba que ese dictamen tenía fuerza

\footnotetext{
100 “Elecciones sindicales.”, Mundo Obrero, Año IV, nº201, del 05-11 al 11-11-1982. pp. 19-21.

101 “Con un 35.8\% CCOO se mantiene la primera.", Mundo Obrero, Año IV, nº202 del 12-11-1982 al 1811-1982. pp. 38-39.

102 “Ganar las Elecciones Sindicales.”, Mundo Obrero, Año IV, n²04, del 26-11 al 02-12-1982. pp. 2425.

${ }^{103}$ Antón Saracibar, “Aproximación a un segundo análisis.”, Unión, n³0, 15-10-1982, pp. 4-5.

104 "El Consejo de Estado respalda las tesis de Comisiones Obreras sobre el cómputo del resultado de las elecciones sindicales.", El País, 27-11-1982.
} 
moral y que sería grave que el nuevo gobierno socialista no lo tuviera en cuenta ${ }^{105}$. Gaceta sindical se apuntó el tanto de la resolución del Consejo de Estado a favor de contabilizar desde la fecha del 1 de enero de $1981^{106}$. Mundo Obrero también difundió el dictamen del Consejo de Estado, aunque expresaba el temor de que el nuevo gobierno no lo tuviera en cuenta, contabilizando solo desde el 15 de marzo de 1982 hasta el 31 de diciembre de $1982^{107}$.

Como vemos los resultados son contradictorios, y la fecha de inicio del cómputo tampoco está clara, por lo que $\mathrm{CCOO}$ en la reunión de su Secretariado del 27 de noviembre volvió a plantearse dar la batalla en los IMAC provinciales, de donde parten los datos para el IMAC nacional. A la vez volvió a proponer a la organización centrarse en Madrid y Barcelona en los procesos electorales que quedaban por realizar ${ }^{108}$.

En resumen, en noviembre, estábamos ante una confrontación clara entre los dos sindicatos respecto a la fecha de inicio del cómputo y los resultados electorales (cada sindicato se consideraba ganador en función de la fecha de inicio del cómputo). Además, existían casos de fraude, sin duda graves, pero que eran usados para la confrontación y para deslegitimar a UGT. Todo ello mientras la maquinaria electoral continuaba funcionando y se seguía luchando por el triunfo voto por voto.

\section{LA RECTA FINAL DE LAS ELECCIONES Y LA UNIDAD SINDICAL}

Cuando en diciembre de 1982 tomó posesión Felipe González como presidente del Gobierno entrabamos en la recta final de unas elecciones sindicales con enfrentamientos sobre la fecha de inicio del cómputo y sobre quien iba ganando las mismas. Una dinámica de confrontación que rompió Marcelino Camacho con un sorpresivo llamamiento a la unidad sindical, el cual fue aprobado con dos votos en

\footnotetext{
105 “UGT defenderá el 15 de marzo como inicio del cómputo electoral.”, El País, 28-11-1982.

106 “El Consejo de Estado da la razón a CCOO.", Gaceta Sindical, n²2, Año III, p. 31.

107 "El Consejo de Estado da la razón a CCOO.”, Mundo Obrero, Año IV, n²05, del 03-12-1982 al 0912-1982. p.24.

${ }^{108}$ Acta de la reunión ordinaria del Secretariado Confederal del día 27/11/82. Punto 2. Elecciones sindicales", Eduardo Saborido, apuntes anexos a dicha acta, AHCCOO-A, Comisiones Obreras de Andalucía, Caja 1.
} 
contra en el Secretariado de CCOO, uno de ellos el de Julián Ariza, que habló de la inoportunidad de la declaración ${ }^{109}$. Mari Paz Pardo en esa reunión criticó que se estuviera dando la impresión de ir perdiendo frente a UGT ${ }^{110}$. A pesar de las críticas, la propuesta fue trasladada al Consejo Confederal y ratificada por 109 votos a favor y 7 abstenciones. Esta estrategia se fundamentaba en la trayectoria histórica de CCOO por la unidad sindical a través del Congreso Sindical Constituyente, la Coordinadora de Organizaciones Sindicales y el fortalecimiento de los comités de empresa. El Consejo Confederal afirmaba que la unidad sindical era necesaria para el fortalecimiento de la clase trabajadora en esa etapa de crisis y desempleo que estaba teniendo lugar. Se propuso a la UGT la creación de un órgano de cooperación interconfederal que en lo inmediato debería abordar los siguientes $\operatorname{puntos}^{111}$ :

-1) Negociación colectiva y concertación con el gobierno.

-2) Acercar la acción sindical en las empresas.

-3) Acuerdos en sectores con problemas puntuales.

Gaceta Sindical interpretó que la apuesta por la unidad iba en función de desligar al sindicato UGT del PSOE, para evitar que este sindicato se gubernamentalice y que el PSOE se derechice ${ }^{112}$.

El diario El País hablaba del modelo italiano, se trataría de una unidad que no fuera solo de cúpulas, una unidad donde se respetara la pluralidad interna. Por otro lado, aunque no existió respuesta oficial de UGT, si respondió de forma oficiosa Manuel Chaves (que ejercía de enlace entre PSOE y UGT). Manuel Chaves consideró esta estrategia una forma de influir en el voto en las elecciones sindicales y de encubrir el desastre producido por la crisis interna del $\mathrm{PCE}^{113}$.

\footnotetext{
109 Acta de la reunión ordinaria del Secretariado Confederal del día 01/12/82 Punto 3. Elecciones Sindicales, Eduardo Saborido, apuntes anexos a dicha acta, AHCCOO-A, Comisiones Obreras de Andalucía, Caja 1.

110 Acta de la reunión ordinaria del Secretariado Confederal del día 01/12/82. Punto 3. Elecciones Sindicales, Eduardo Saborido, apuntes anexos a dicha acta, AHCCOO-A, Comisiones Obreras de Andalucía. Caja 1.

111 Acta de la reunión ordinaria del Consejo Confederal del día 12/12/82. Punto 1. Análisis de la situación, AHCCOO-A, Comisiones Obreras de Andalucía. Caja 132.

112 Marcelino Camacho, "La unidad sindical es el sentimiento mayoritario los trabajadores.", Gaceta Sindical, n²3, Año IV, pp. 22-31.

113 "Marcelino Camacho insiste en la necesidad de lograr la fusión de Comisiones Obreras y Unión General de Trabajadores.", El País, 02-12-1982.
} 
La interpretación de Manuel Chaves era una interpretación despectiva. Pudieran ser otras las causas de la propuesta de unidad sindical, entre ellas captar los últimos votos indecisos en las elecciones sindicales, romper con la imagen de la clase obrera dividida y terminar con la apariencia de confrontación sindical. Mi interpretación es que se trataría de una salida hacia delante, conseguir que tras las dos elecciones (sindicales y políticas) CCOO continúe con su lucha, ya bajo un gobierno socialista.

El 21 de diciembre en la reunión del Secretariado de CCOO no se hablaba claramente de triunfo electoral, solo se instaba a la comprobación de datos de los resultados electorales y a mantener el trabajo electoral hasta el último día, es decir hasta el 31 de diciembre. Además, se acordó mantener los liberados sindicales hasta enero de 1983 para detectar los posibles fraudes en el recuento y en las actas ${ }^{114}$.

Este silencio interno sobre resultados de CCOO contrastaba con los datos de la Comisión Ejecutiva de UGT que el 20 de diciembre era ya conocedora de que los resultados electorales le eran favorables sea cual fuere la fecha de cómputo electoral. La Comisión Ejecutiva de UGT optó por la discreción en vez de por la euforia y tomó la decisión de esperar a la reunión del IMAC estatal para hacer pública la victoria ${ }^{115}$.

Antón Saracibar en El Socialista proclamó la victoria, incluso contabilizando desde enero de 1981, tal como pide CCOO. Eligiera el periodo de cómputo que se eligiera, UGT sería el primer sindicato. Este sindicato obtendría un 38\% de los delegados, frente a un $35 \%$ de $\mathrm{CCOO}^{116}$. Unión hablaba del $38.21 \%$ de los delegados para UGT, mientras que CCOO solo obtendría el $35.36 \%$, realizando también un desglose de datos regionales y provinciales ${ }^{117}$. En el suplemento de la segunda quincena de diciembre se volvían a dar datos, pero esta vez reflejo de los IMAC provinciales, contabilizando desde el 15 de marzo de 1982 al 10 de diciembre de 1982, en ellos UGT obtiene el $37.60 \%$ de los votos y CCOO el $34.42 \%{ }^{118}$.

\footnotetext{
114 Acta de la reunión ordinaria del Secretariado Confederal del día 21/12/82. Punto 3. Elecciones Sindicales, Eduardo Saborido, apuntes anexos a dicha acta, AHCCOO-A, Comisiones Obreras de Andalucía, Caja 1.

115 "Acta de la Reunión de la Comisión Ejecutiva Confederal del 20.12.82. Punto III. Elecciones Sindicales", Fondo UGT, Sig. 002560-001 a 002564-003, AFFLC.

${ }^{116}$ Antón Saracibar, "Elecciones Sindicales 82: Un primer análisis.”, El Socialista, n²89, del 20-12-1982 al 28-12-1982. pp. 28-29.

117 “UGT va ganando.", Unión, nº33, 03-12-1982, pp. 1-2, 10-12.

118 “Los técnicos, su participación en el cambio.", Unión, n³4, 15-12-1982, pp. 10-12.
} 
El 24 de diciembre aparecieron datos oficiales del IMAC, que son rechazados por CCOO debido a que fueron contabilizados desde 1 de enero de 1982 hasta el 30 de noviembre de 1982 y porque se había procedido a publicar datos facilitados telefónicamente por los IMAC provinciales al IMAC nacional ${ }^{119}$.

Mundo Obrero no reconoció la victoria el 24 de diciembre, y se centró en ejemplos de fraudes en actas realizadas por la UGT en empresas pequeñas, donde se cambiaba el acta camino al IMAC, asignándose UGT los delegados o se inventaban elecciones que no se habían producido ${ }^{120}$. En enero de 1983 la revista volvía a hablar de fraude y se hacía portavoz del rechazo de CCOO a los datos del IMAC. Según la revista las actas provisionales no habían sido todavía firmadas y existían actas fraudulentas impugnadas que habían sido contabilizadas como válidas. Creían que el nuevo Director General del IMAC (socialista) continuaba con las mismas prácticas de falta de imparcialidad que el anterior de la $\mathrm{UCD}^{121}$.

Sobre todos los tipos de fraudes denunciados por CCOO y por Mundo Obrero desconocemos la cantidad y si fue algo generalizado. Habría que investigar más al respecto. Si tenemos referencias de que en las siguientes elecciones sindicales de 1986 existían prácticas empresariales conocidas como "el señor maletín" que visitaba los polígonos industriales buscando el voto a favor de UGT. Habría por tanto que indagar si esto también sucedió en las elecciones sindicales de 1982, e incluso en elecciones anteriores $^{122}$.

Por contra a las dudas expresadas por Mundo Obrero, Antón Saracibar entregó a la Ejecutiva de UGT el 10 de enero de 1983 datos del IMAC a fecha 31 de diciembre de 1982, que dan la victoria a este sindicato y se acuerda realizar un encuentro con la

\footnotetext{
119 "Nueva polémica sobre los resultados de las elecciones sindicales.", El Pais, 24-12-1982.

120 “Más denuncias de fraude.”, Mundo Obrero, Año IV, n²08, del 24-12-1982 al 30-12-1982. pp. 32-33.

121 "CCOO rechaza los datos del IMAC.", Mundo Obrero, Año IV, n²09, del 31-12-1982 al 06-01-1983. p. 24.

${ }^{122}$ Sergio Gálvez Biesca. "III. La construcción de la «Unidad de acción» sindical.”, en La gran huelga general: El sindicalismo contra la «modernización socialista». (Madrid: Siglo XXI de España Editores, 2018). p. 6.
} 
prensa para difundirlos ${ }^{123}$. Con posterioridad estos datos no se hicieron públicos, debido a que se estaban revisando los que procedían de los IMAC provinciales ${ }^{124}$.

El Secretariado de CCOO del 4 de enero, continuaba con el silencio interno respecto a resultados y se volvió a centrar en revisar todas las actas hasta el 31 de diciembre, en no dejar pasar ni un acta mala, así como revisar actas subsanables ${ }^{125}$.

Por tanto, a finales de diciembre y principios de enero nos encontramos con que ya se habla de victoria de UGT, aunque mediante datos filtrados por el IMAC. Comisiones Obreras, aunque rechazó estos datos, no lo contrarrestó con otros alternativos, sino que opta por un llamamiento a la unidad sindical en la época de crisis en que se encontraba el país.

\section{LA VUELTA A LA RUTINA}

Mediante la expresión "vuelta a la rutina" me refiero a una serie de asuntos de la actividad sindical diaria que hicieron pasar a un segundo plano la contienda electoral. E1 primer asunto fue la negociación colectiva, que iba por la cuarta ronda negociadora, en la cual a la altura del 4 de enero de 1983 continuaba el desacuerdo en temas como la entrada en vigor de la reducción de jornada o la revisión de los salarios de los convenios respecto al IPC ${ }^{126}$. El 13 de enero la CEOE propuso un crecimiento de los salarios entre dos y seis puntos por debajo del IPC algo que rechazaban los sindicatos $^{127}$. Entretanto el gobierno decretó el salario mínimo para 1983 de 1071 pesetas al día, con un incremento del 13\%, que es mayor que la banda del $6 \%$ al $10 \%$

\footnotetext{
${ }^{123}$ Acta de la Reunión de la Comisión Ejecutiva Confederal del 10.01.83. Punto II. Elecciones Sindicales, AFFLC, Fondo UGT, Sig. 002560-001 a 002564-003.

124 Acta de la Reunión de la Comisión Ejecutiva Confederal del 28.01.83. Punto IV. Elecciones Sindicales, AFFLC, Fondo UGT, Sig. 002560-001 a 002564-003.

125 Acta de la reunión ordinaria del Secretariado Confederal del día 05/01/83. Punto 3. Elecciones Sindicales, Eduardo Saborido, apuntes anexos a dicha acta, AHCCOO-A Comisiones Obreras de Andalucía, Caja 235.

126 “Sin acuerdo en la reunión para la negociación colectiva para este año.”, $A B C, 05-01-1983$. p. 40.

127 “La CEOE propone un incremento de los salarios para 1983 entre dos y seis puntos por debajo de la inflación prevista.”, El País, 13-01-1983.
} 
que había propuesto CEOE para sus asalariados ${ }^{128}$. La negociación estuvo a punto de fracasar, según Nicolás Redondo ${ }^{129}$. Tuvo que intervenir Felipe González el día 26 de enero para evitar la ruptura, entrevistándose con Carlos Ferrer (CEOE) y Nicolás Redondo (UGT) ${ }^{130}$. El día 30 de enero se alcanzó un preacuerdo consistente en una banda salarial entre el $9.5 \%$ y el 12.5\%. ${ }^{131}$ También se consiguió la revisión de la banda salarial a los nueve meses y una jornada anual de 1826 horas y 27 minutos $^{132}$. CEOE, UGT y CCOO asumieron el Acuerdo Interconfederal de 1983 en sus respectivos órganos, y se produjo la firma de este el 15 de febrero de $1983^{133}$.

El segundo tema que devolvió a los sindicatos a la rutina fue la reconversión industrial. El problema afectó a Gijón, donde se produjo una huelga general que secundó el 100\% de los trabajadores y sacó a cien mil personas a las calles ${ }^{134}$. En Gijón existía una industria pesada de carbón y siderurgia que no se diversificaba hacia la transformación del metal, la carboquímica o la agroalimentación. La decadencia de estas grandes industrias llevaba al cierre y al aumento del desempleo en las pequeñas industrias subsidiarias ${ }^{135}$.

Sagunto también sufría la reconversión industrial debido al anuncio del cierre del horno número dos de AHM. La contestación a este anuncio llevó a la paralización de todo el pueblo el día 16 de febrero de 1983, mediante una exitosa huelga general y una manifestación de treinta mil personas, que contaron con el apoyo de los sindicatos, del alcalde socialista y del presidente de la Diputación de Valencia. La medida de la empresa pública fue revocada desde industria. En la manifestación se pudieron escuchar los gritos de "Felipe, Guerra, Sagunto no se cierra"136.

\footnotetext{
128 “El gobierno fijará el salario mínimo en 1071 pesetas.”, El País, 15-01-1983.

129 “La concertación social puede llegar a su fin, según Nicolás Redondo.”, El País, 20-01-1983.

130 "Situación de pre-ruptura en la concertación.", $A B C, 27-01-1983$. p. 47.

131 "Empresarios y sindicatos ultimaron ayer el Acuerdo Interconfederal-83.”, $A B C, 27-01-1983$. p. 47.

132 "Sindicatos y patronal continúan la negociación, tras despejar las incógnitas sobre banda salarial, revisión y jornada.”, El País, 31-01-1983.

133 “Firmado el Acuerdo Interconfederal para 1983.”, El País, 16-02-1983.

134 “Gijón quedó ayer totalmente paralizado por una huelga general secundada por el $100 \%$ de los trabajadores.", El Pais, 26-01-1983.

${ }^{135}$ Ignacio Alonso, "La crisis industrial de Gijón aviva la tensión social en Asturias.”, El País, 30-011983.

136 “Huelga General en Sagunto contra el cierre de Altos Hornos del Mediterráneo.”, El País, 17-02-1983.
} 
Por último, las primeras medidas tomadas por el gobierno en cuestión de pensiones, salario mínimo y cotizaciones de la seguridad social también concentraron el trabajo sindical. Fueron criticadas por CCOO en base a que no se había consultado a los sindicatos, a que la subida de las pensiones más bajas era solo una redistribución interna entre el conjunto de pensionistas, y a que la reducción del 1.5\% de las cotizaciones de la seguridad social se realizaba sobre la parte empresarial. UGT no comparte estas opiniones $^{137}$.

La vuelta a la rutina se compaginó con los últimos coletazos de la polémica del resultado de las elecciones sindicales. El 4 de enero de 1983 Marcelino Camacho actuó de forma ambivalente, por una parte, continuó proclamando la victoria de CCOO y por otra remó a favor de la unidad sindical, al dejar claro que lo importante era el avance de los sindicatos de clase ${ }^{138}$. En realidad, las derrotas se pueden asumir de forma explícita o implícitamente, este sería el segundo caso para CCOO. En la Comisión Ejecutiva de CCOO del 11 de enero se habló de que se había ganado en las grandes capitales y en las grandes empresas, con lo cual se estaba reconociendo de alguna forma la derrota en el resto de los ámbitos ${ }^{139}$.

El Socialista proclamó la victoria de UGT en enero de 1983. Según datos oficiosos, con un $48 \%$ de las actas comprobadas, UGT había conseguido 53688 delegados, frente a los 48002 de CCOO, lo que daría un $36.70 \%$ a UGT, frente a un $32.82 \%$ de delegados de CCOO. Estos resultados fueron contabilizados a partir del 15 de marzo de $1982^{140}$. Unión refiere datos de los IMAC provinciales que también le daban un $36.70 \%$, frente a un $32.82 \%$ de CCOO. Afirmaba que CCOO había realizado acusaciones de fraude contra UGT para crear mala imagen, pero que ya no había lugar para esta estrategia, puesto de UGT había ganado ${ }^{141}$. Todo ello fue remachado en prensa por Antón Saracibar, que quería zanjar la cuestión sobre quien había ganado las elecciones sindicales basándose en la publicación de los datos provisionales provinciales

\footnotetext{
137 "Comisiones Obreras critica con dureza las medidas sobre Seguridad Social y pensiones.” El País, 2201-1983.

138 "Marcelino Camacho afirma que en las elecciones ha triunfado el sindicalismo de clase.", El País, 0401-1983.

139 Acta de la reunión ordinaria de la Ejecutiva Confederal del día 11/01/83. Punto 3. Elecciones Sindicales, Eduardo Saborido, apuntes anexos a dicha acta, AHCCOO-A, Comisiones Obreras de Andalucía, Caja 233.

140 “UGT, una victoria casi oficial.”, El Socialista, n²93, del 19-01-1983 al 25-01-1983. pp. 26-27.

141 “UGT primera fuerza sindical.”, Unión, n³6, 15-01-1983, pp. 1-2 ,9-12.
} 
del IMAC, de ellos se desprendía que tanto si se partía desde el 1 de enero de 1981, desde el 1 de enero de 1982 o desde el 15 de marzo de 1982, en todos los casos había ganado UGT las elecciones sindicales. Solo variaban los porcentajes de esta victoria ${ }^{142}$.

Pero sea o no cierto los datos de Antón Saracibar, oficialmente el IMAC debía decidir la fecha de inicio del cómputo electoral y lo hizo en una reunión del 10 de febrero de 1983, donde tomó la determinación de contabilizar desde el 15 de marzo de $1982^{143}$. Los resultados oficiales del IMAC fueron difundidos por UGT. Desde el 15 de marzo hasta el 31 de diciembre la UGT ganó por el 36.7\% de los votos obteniendo 51662 delegados. Le seguía CCOO con el 33.4\% de los votos y 47023 delegados. Los demás sindicatos quedaban muy alejados de los dos primeros, así el tercero era USO con el 4.64\% y 6627 delegados y la victoria de ELA en Euskadi ${ }^{144}$.

Navarro Botella en 1983 expone los mismos datos del IMAC, pero más detallados, especificando que no participó el 53.2\% de los trabajadores (por abstención o por no realizarse elecciones en su empresa) y si participó el $46.8 \%$, lo cual representa tres millones cincuenta mil de trabajadores. UGT obtuvo el $36.7 \%$ de los votos, CCOO el 33.4\%, USO el 4.6\%, ELA-STV el 3.3\% e INTG el 1.2\% y los no afiliados el $12.1 \%$. UGT aumenta 7.3 puntos respecto a las elecciones de 1980 y CCOO ha aumentado 2.7 puntos respecto a las de 1980. UGT obtuvo 3.3 puntos más que CCOO, debido a la bajada de un 10.8 del resto de sindicatos (con excepción de los sindicatos nacionalistas) ${ }^{145}$.

A pesar de estos datos oficiales del IMAC, el Secretariado de CCOO da una serie de datos frente a ellos, entre los cuales está que CCOO ganó en las empresas de más de 250 trabajadores, que UGT solo ganó en las empresas de menos de 50 trabajadores, que CCOO tenía más votos que UGT y que el IMAC no había sido imparcial. En esa reunión del Secretariado de CCOO se habló de pucherazo y de

\footnotetext{
${ }^{142}$ Antón Saracibar, “Elecciones Sindicales 1982.”, El País, 01-02-1983.

${ }^{143}$ Acta de la reunión de la Comisión Ejecutiva Confederal del 08.02.83. Punto III. Elecciones Sindicales, AFFLC, Fondo UGT, Sig. 002560-001 a 002564-003.

144 "UGT venció en las elecciones sindicales, según datos oficiales aportados por el propio sindicato.", El Pais, 09-03-1983.

${ }^{145}$ Francisco José Navarro Botella. Las elecciones..., op.cit., pp. 13-18.
} 
levantarse de la reunión del IMAC que aprobaría los resultados ${ }^{146}$. Con posterioridad, Mundo Obrero esgrimió contra estos datos los motivos de haber desoído al Consejo de Estado, los de proclamar actas impugnadas por CCOO o de dar por válidos para UGT los delegados de SOMA bajo otras siglas afines a UGT como razones de impugnación de los resultados por parte de $\mathrm{CCOO}^{147}$.

Por el contrario, el resultado oficial si fue reconocido con alegría por UGT en la revista Unión del 10 de marzo. En portada, aunque escueto, se reflejaron los resultados oficiales y se hablaba de que UGT era la central hegemónica con un $36.7 \%$ de los delegados, mientras que CCOO obtiene el $33.4 \%{ }^{148}$. Antón Saracibar afirmó que las denuncias de fraude, la negativa a firmar el acta del IMAC y el posible recurso del tiempo de cómputo al Tribunal Constitucional eran solo una pataleta de CCOO sin consecuencias $^{149}$.

Hubo que esperar a la víspera del 1 de mayo, para que Marcelino Camacho llegara a reconocer la derrota electoral en Mundo Obrero, aunque lo hiciera enmascarándola entre muchos datos favorables para CCOO. Marcelino refirió un aumento de delegados de CCOO respecto a 1980, una subida del 2.5\% (del 30.89\% al $33.4 \%$ ), un aumento de número de delegados y un aumento de votos para CCOO. Solo tras referir todos esos datos reconoció que UGT se había situado ligeramente por encima de CCOO, aunque lo achacaba al fraude en las elecciones ${ }^{150}$.

\section{CONCLUSIONES}

Las elecciones sindicales de 1982 eran unas elecciones transcendentales por su coincidencia con un importante cambio político que daría el poder a la izquierda por

\footnotetext{
146 Acta de la reunión ordinaria del Secretariado Confederal del día 08/03/83. Punto 1. Elecciones Sindicales, Eduardo Saborido, apuntes anexos a dicha acta, AHCCOO-A, Comisiones Obreras de Andalucía. Caja 235.

147 “CCOO no acata los resultados del IMAC.", Mundo Obrero, Año V, n²20 del 11-03-1983 al 17-031983. pp. 24-25.

148 “UGT, Central hegemónica.”, Unión, n³8, 10-03-1983, p. 1.

149 "El voto sindical más cerca del político.", El Socialista, n³01, del 16-03-1983 al 22-03-1983. pp. $27-$ 28.

${ }^{150}$ Marcelino Camacho, "El Primero de Mayo tiene que ser reivindicativo.", Mundo Obrero, Año V, n²26, Del 29-04-1983 al 05-05-1983, pp. 20-21.
} 
primera vez tras cerca de cuarenta años de la dictadura del General Franco y una transición capitaneada por gobiernos de centro de tipo moderado. La enorme victoria del PSOE no se correspondía con la misma correlación de fuerzas en el ámbito sindical, debido a la fortaleza del sindicato Comisiones Obreras. Por ello UGT aspiraba a tener una victoria análoga que diera el poder a la familia socialista en todos los ámbitos, incluido el sindical. La victoria de UGT no sería fácil y en ninguna forma tan amplia como la del PSOE. Por el contrario, sería cuestionada por CCOO hasta el último momento. CCOO aspiraba a seguir manteniendo su hegemonía sindical, a pesar de la debacle de su fuerza política hermana, el Partido Comunista de España. La aspiración de CCOO era la de modificar o redirigir hacia la izquierda el proyecto de política económica del PSOE desde la hegemonía sindical, algo que no consiguió, pero si lo siguió intentando desde una fuerte segunda opción sindical a muy poca distancia de UGT. Para ello también luchará por separar o desvincular en parte a UGT de la política económica de su partido hermano.

Por otra parte, estas elecciones culminaban un proceso de fortalecimiento de una UGT que llegó en condiciones de debilidad frente a unas Comisiones Obreras mucho más fuertes. Fortaleza de CCOO debida a su infiltración en el Sindicato Vertical durante la dictadura. UGT en la mayoría de los casos no practicó esta política de infiltración. Dado que CCOO era mayoritaria en los comités de empresas y su política era asamblearia (dando participación en las decisiones asamblearias tanto a trabajadores afiliados como a no afiliados), UGT apostó por fortalecerse tras la dictadura en base a sus afiliados y sus secciones sindicales, apoyándose en los pactos sociales que hemos resumido al principio de este artículo y en el Estatuto de los Trabajadores. Estas elecciones supusieron pues una consolidación de esta estrategia de fortalecimiento sindical y llevaron a la victoria de UGT en las elecciones sindicales de 1982.

Centrado en los hechos descritos, estas elecciones sindicales se desarrollaron con varias controversias de fondo, entre ellas la oportunidad o no de realizarlas coincidiendo con las elecciones generales, el periodo de cómputo, así como las denuncias de diferentes tipos de fraude e impugnaciones de resultados.

Existía un debate jurídico sobre quien llevaba la razón sobre el periodo de cómputo de los datos electorales. CCOO afirmaba que las anteriores elecciones sindicales finalizaron el 31 de diciembre de 1980, y que sería a partir del 1 de enero de 1981 hasta el 31 de diciembre de 1982 el tiempo de cómputo, dado que abarcaría todas 
las elecciones de empresas de ese periodo. Por su parte UGT consideraba que el Estatuto de los Trabajadores no regulaba el periodo de cómputo y que en las anteriores elecciones se situó entre marzo y diciembre de 1980 y en las de 1982 debía hacerse igual, es decir desde el 15 de marzo de 1982 hasta el 31 de diciembre de 1982. El debate se resolvería años después, primero alargando el periodo electoral de dos a cuatro años y a partir de 1995 con un registro electoral permanente (que es el modelo actual) ${ }^{151}$.

Considero que no debemos centrarnos en el debate jurídico, sino en las estrategias sindicales y políticas. De este artículo se desprende en primer lugar que a UGT no le interesaba realizar elecciones sindicales en 1982, prefería realizarla después de las elecciones generales, bajo un gobierno socialista. Sin embargo, esta oposición a realizar elecciones sindicales no implicaba que no estuvieran preparados para afrontarlas, pues conocían que para una prórroga era necesario cambiar la ley, lo cual era muy difícil, pues el PSOE no tenía mayoría en el Congreso. Contrariamente a UGT, CCOO no quería que se demoraran los comicios porque era la fuerza hegemónica y porque este sindicato creía estar preparado para volver a ganar en las empresas.

La polémica del periodo de cómputo electoral no es una polémica que se produjera al principio, sino a mediados y finales del periodo electoral. Hasta final del verano no empezó a haber declaraciones contradictorias sobre la fecha de cómputo electoral. La polémica se acrecentó a partir de que los resultados que se filtran del IMAC empezaron a ser desfavorables para $\mathrm{CCOO}$, produciéndose una agria discusión al respecto en la recta final de las elecciones. Esta polémica finalizaría con el desconocimiento de los resultados por parte de CCOO y el anuncio de la impugnación de estos por la vía judicial.

Las argumentaciones de CCOO son refutadas por los hechos acaecidos:

1) Las declaraciones de los dos sindicatos en sus órganos internos, donde se repetía que "el grueso" de las elecciones se producirían a partir de septiembre, con lo cual minimizaban ellos mismos el resto de los procesos electorales en empresas anteriores a ese mes.

2) La organización que quería extender el periodo electoral desde 1 de enero de 1981 (CCOO), no mencionó las elecciones por primera vez hasta el Secretariado del 16 de febrero de 1982 y no trató el proceso electoral hasta

\footnotetext{
${ }^{151}$ Antonio Ojeda Avilés, \& Jesús Maetzu Gregorio de Tejada, "Elecciones a representantes de personal y promoción de los sindicatos más representativos en la ley 8/1980”. Revista De Política Social, n¹37, (1983): 251-301.
} 
el Secretariado del 2 de marzo de 1982, siendo las reuniones organizativas al respecto a partir de mayo de 1982.

3) A partir de que los datos de los IMAC provinciales empezaron a ser desfavorables fue cuando CCOO empezó a pedir públicamente se retrotrajera la fecha de inicio del cómputo, primero a enero de 1982 y luego al 1 de enero de 1981.

Como observamos los puntos 1 y 2 se contradicen con el punto 3. ¿Cómo una organización que quería se contabilizaran las elecciones desde el 1 de enero de 1981 no empezó a hablar de ellas hasta marzo de 1982 y no realizó el grueso de las elecciones hasta septiembre de 1982 ?

Mi tesis al respecto es que $\mathrm{CCOO}$ fue evolucionando sus argumentos a medida que empezó a verle "las orejas al lobo", es decir a medida que los datos filtrados por el IMAC empezaron a serles contrarios. Y que cuando comprobó que ya eran irrevocables realizó dos estrategias: La denuncia pública del fraude de actas y la unidad sindical.

Este proceso electoral no fue un proceso electoral simple, fue un proceso largo y complejo, en el cual se produjeron casos de fraude. El fraude de actas tiene una base en casos reales de connivencia de UGT con pequeños empresarios para que el delegado fuera de UGT. Existen varios ejemplos en Mundo Obrero, pero de ningún modo se puede generalizar y extender el fraude a todas las pequeñas empresas.

La estrategia de la unidad sindical que propone Marcelino Camacho tampoco se puede considerar una forma movilizar el voto de última hora en diciembre, dada la trayectoria de apoyo a la unidad sindical que CCOO capitaneaba desde la clandestinidad. Habría que verla más bien como la forma de volver a la normalidad, al trabajo diario, llamando a fortalecer a los trabajadores en la nueva etapa socialista, para que el nuevo gobierno no se moderara (o derechizara), para rectificar la política económica del PSOE hacia la izquierda y para hacer frente a la crisis económica en general. Para llamar después del resultado de las elecciones sindicales, o incluso sin resolver este resultado, a enfrentarse a las primeras medidas del gobierno socialista sobre seguridad social y pensiones, a la negociación colectiva con la patronal y a las amenazas de reconversión industrial en las grandes empresas estatales en el norte y el levante. Y aunque CCOO no obtuviera el primer puesto, desde el segundo puesto quería arrastrar a UGT hacia sus posiciones y desvincular a este sindicato socialista un poco de las posiciones gubernamentales. 
Lo que no cabe duda es el triunfo de UGT en las elecciones sindicales de 1982, según los datos del IMAC que constata Navarro Botella ${ }^{152}$, y que CCOO solo intentó varias estrategias fallidas para evitar perderlas y para retomar el pulso sindical. Considero que Marcelino Camacho no debió sentirse orgulloso de estas elecciones, dado que en sus memorias no las menciona ${ }^{153}$.

Hubo que esperar a abril de 1983 para que Marcelino Camacho reconozca que UGT superó ligeramente a CCOO. Posiblemente Marcelino lo supiera desde diciembre y esta fue una de las causas por las que quiso recuperar el proyecto de unidad sindical $^{154}$.

\section{BIBLIOGRAFÍA}

Andrade Blanco, Juan Antonio. El PCE y el PSOE en (la) transición: La evolución ideológica de la izquierda durante el proceso de cambio político. Madrid: Siglo XXI. 2012.

Camacho, Marcelino. Confieso que he luchado: Memorias. Madrid: Temas de hoy. 1990.

De Esteban, Jorge. "El proceso constituyente español, 1977-78", editado por José Félix Tezanos, Ramón Cotarelo \& Andrés de Blas, La transición democrática española, 275-316. Madrid: Editorial Sistema, 1989.

Gálvez Biesca, Sergio. La gran huelga general: El sindicalismo contra la «modernización socialista». Madrid: Siglo XXI de España Editores. 2018.

Köhler, Holm-Detlev. El movimiento sindical en España: Transición democrática, regionalismo, modernización económica. Madrid: Fundamentos. 1995

Marín Arce, José María. "Les organitzacions socials durant la transició: Sindicats i patronal, Lluís Bassett \& Pere Ysas (eds.), La configuració de la democràcia a Espanya.", 93-139. Vic: Eumo Editorial, 2009:

Navarro Botella, Francisco José. Elecciones sindicales 1980 : Las expectativas sindicales de los trabajadores españoles. Madrid : Fundación Friedrich Ebert.1982.

Navarro Botella, Francisco José. Las elecciones sindicales 1982. Madrid: Fundación Friedrich Ebert, 1983.

\footnotetext{
${ }^{152}$ Francisco José Navarro Botella. Las elecciones..., op. cit., pp. 13-18.

${ }^{153}$ Marcelino Camacho, Confieso...,op. cit., pp. 456-469.

${ }^{154}$ Marcelino Camacho, "El Primero de Mayo tiene que ser reivindicativo.", Mundo Obrero, Del 29-041983 al 05-05-1983, Año V, n²2, pp. 20-21.
} 
Ojeda Avilés, Antonio, \& Maetzu Gregorio de Tejada, Jesús, "Elecciones a representantes de personal y promoción de los sindicatos más representativos en la ley 8/1980”. Revista De Politica Social. n¹37, (1983): 251-301.

Soto Carmona, Álvaro, "Comisiones Obreras en la transición y consolidación democrática: De la asamblea de Barcelona a la huelga general del 14-D (19761988)", Dir. por José Babiano \& David Ruiz, Historia de Comisiones Obreras (1958-1988), 451-521. Madrid: Siglo XXI de España Editores, 1994.

Vega García, Rubén, La reconstrucción del sindicalismo en democracia, 1976-1994. Historia de la UGT. Vol.6. $1^{\text {a }}$ ed. Madrid: Siglo XXI de España Editores, 2011.

Zaragoza, Ángel. Pactos sociales, sindicatos y patronal en España. Madrid: Siglo XXI de España Editores, 1990.

\section{FUENTES PRIMARIAS}

- AHT-FPM. Archivo de Historia del Trabajo. Fundación $1^{\circ}$ de Mayo.

AHCCOO-A. Archivo Histórico de Comisiones Obreras de Andalucía.

- AFLC. Archivo de la Fundación Largo Caballero.

- Revista Mundo Obrero.

- Revista El Socialista.

- Revista Gaceta Sindical.

- Revista Unión.

- Diario El País.

- Diario $A B C$. 